\title{
Effects of coronal substrates and water storage on the microhardness of a resin cement used for luting ceramic crowns
}

\author{
Luana Menezes de MENDONÇA', Luiz Fernando PEGORARO'1, Marcos Daniel Septímio LANZA', Thiago Amadei \\ PEGORARO², Ricardo Marins de CARVALHO ${ }^{3}$ \\ 1- Department of Prosthodontics, Bauru School of Dentistry, University of São Paulo, Bauru, SP, Brazil. \\ 2- Department of Prosthodontics, Sagrado Coração University, Bauru, SP, Brazil. \\ 3- Department of Oral Biological and Medical Sciences, Division of Biomaterials, Frontier Clinical Research Centre, The University of British Columbia, Faculty \\ of Dentistry, Vancouver, BC, Canada.
}

Corresponding address: Luiz Fernando Pegoraro - Departamento de Prótese - Faculdade de Odontologia de Bauru - Universidade de São Paulo - Alameda Doutor Octávio Pinheiro Brisolla, 9-75 - Vila Nova Cidade Universitária - Bauru - SP, Brazil - 17012-901 - e-mail: pegoraro@fob.usp.br

Submitted: September 9, 2013 - Modification: March 14, 2014 - Accepted: April 7, 2014

\section{ABSTRACT}

\begin{abstract}
Composite resin and metallic posts are the materials most employed for reconstruction of teeth presenting partial or total destruction of crowns. Resin-based cements have been widely used for cementation of ceramic crowns. The success of cementation depends on the achievement of adequate cement curing. Objectives: To evaluate the microhardness of Variolink ${ }^{\circledR}$ II (Ivoclar Vivadent, Schaan, Liechtenstein), used for cementing ceramic crowns onto three different coronal substrate preparations (dentin, metal, and composite resin), after 7 days and 3 months of water storage. The evaluation was performed along the cement line in the cervical, medium and occlusal thirds on the buccal and lingual aspects, and on the occlusal surface. Material and Methods: Thirty molars were distributed in three groups $(\mathrm{N}=10)$ according to the type of coronal substrate: Group D- the prepared surfaces were kept in dentin; Groups M (metal) and R (resin)- the crowns were sectioned at the level of the cementoenamel junction and restored with metallic cast posts or resin build-up cores, respectively. The crowns were fabricated in ceramic IPS e.max ${ }^{\circledR}$ Press (Ivoclar Vivadent, Schaan, Liechtenstein) and luted with Variolink II. After 7 days of water storage, 5 specimens of each group were sectioned in buccolingual direction for microhardness measurements. The other specimens $(\mathrm{N}=5)$ were kept stored in deionized water at $37^{\circ} \mathrm{C}$ for three months, followed by sectioning and microhardness measurements. Results: Data were first analyzed by three-way ANOVA that did not reveal significant differences between thirds and occlusal surface $(p=0.231)$. Two-way ANOVA showed significant effect of substrates $(p<0.001)$ and the Tukey test revealed that microhardness was significantly lower when crowns were cemented on resin cores and tested after 7 days of water storage $(p=0.007)$. Conclusion: The type of material employed for coronal reconstruction of preparations for prosthetic purposes may influence the cement properties.
\end{abstract}

Keywords: Resin cements. Hardness tests. Ceramics.

\section{INTRODUCTION}

Endodontically treated teeth presenting partial or total destruction of crowns require reconstruction to create a core to provide mechanical conditions for the indirect restoration to be fixed and remain in function for a long period. The materials most employed for that purpose are composite resins and cast metallic posts.
Resin-based cements have been widely employed for cementation of metaloceramic or ceramic crowns due to their adhesive capacity to both tooth structure and restoration, combined with esthetic and mechanical properties ${ }^{15,22,25}$. Since the success of cementation depends on the achievement of a strong and long-lasting bond among cement, restoration and tooth structure ${ }^{30}$, the strength of such adhesion procedure is directly proportional to 
the adequate curing of the cement and is crucial to achieve optimal physical and mechanical properties and satisfactory clinical performance?.

Several factors may influence the curing of the cement used for luting ceramic crowns. These include: the composition, thickness, opacity and shade of the ceramic, which may reduce the light transmission and consequently affect

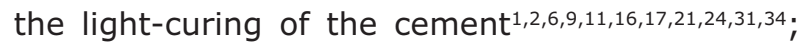
characteristics of substrates and luting agent ${ }^{5,15}$; incompatibility of simplified adhesive systems with self- or dual-cured resin cements ${ }^{23,28,29}$; and permeability of simplified adhesives, which ultimately compromises the bonding between the cement and the adhesive 26,27 .

Considering the lack of information in the literature on the possible influence of the type of material used as coronal reconstruction on the physical properties of the cement used for luting ceramic crowns, this study evaluated the microhardness of the resin cement Variolink ${ }^{\circledR}$ II along the cement line in the cervical, medium and occlusal thirds on the buccal and lingual aspects, and on the occlusal surface, when used for luting ceramic crowns on different substrates (dentin, metal, and composite resin), after 7 days and 3 months of water storage. The null hypotheses tested were that microhardness would not be influenced by the region of prepared surfaces, coronal substrate, and water storage.

\section{MATERIAL AND METHODS}

Thirty human third molars were embedded with plaster in plastic cylinders with the cementoenamel junction approximately $3 \mathrm{~mm}$ above the top of the cylinder. The teeth were prepared with diamond burs for full-ceramic crowns with a shoulder of $1.2 \mathrm{~mm}$ with internal rounded angles, and axial reduction of $1.5 \mathrm{~mm}$ with 6 to $10^{\circ}$ convergence angle was performed. Occlusal reduction was performed resulting in an axial height of 4.0 $\mathrm{mm}$ (Figure 1a). They were randomly divided into 3 groups $(\mathrm{N}=10)$ as follows: Group $\mathrm{D}$ - the prepared crown surface was kept in dentin; Group $M$ - the crowns were sectioned at the level of the cementoenamel junction and the core was modeled in acrylic resin DuraLay (Reliance Dental Mfg. Co. Worth, Illinois, USA), cast in aluminum-copper alloy, and luted with zinc phosphate (S. S. White Artigos Dentários Ltda., Rio de Janeiro, RJ, Brasil); Group $\mathrm{R}$ - the crowns were sectioned as in group $\mathrm{M}$, and filling of the cores was performed with composite resin Filtek ${ }^{\circledR}$ Z250 (3M ESPE, St Paul, MN, USA) by the incremental technique. Light irradiation was obtained from a Quartz Tungsten Halogen (QTH) device V.I.P. Junior (Bisco, Schaumburg, IL, USA, $500 \mathrm{~mW} / \mathrm{cm}^{2}$ ) for $20 \mathrm{~s}$ for each increment, and 40 $\mathrm{s}$ for the last one. The pulp chambers were cleaned and filled with the same composite resin. The reduction, convergence and height of axial walls followed the same principles described above for Group D.

Silicon molds were made of all sound tooth crowns before preparation. These were then used to guide the construction of the ceramic crowns to a thickness of $1.5 \mathrm{~mm}$ on the axial walls and 2.0 $\mathrm{mm}$ on the occlusal surfaces.

On the center of buccal, occlusal and lingual aspects of the prepared surfaces, a relief was made in wax with approximate thickness of $0.25 \mathrm{~mm}$ and width of $2.0 \mathrm{~mm}$ to purposely allow for a thicker cement line and permit the microhardness tests (Figure 1b). Impressions of the preparations were taken with polyvinyl siloxane Express ${ }^{\circledR}$ (3M ESPE, St Paul, MN, USA) and cast with type IV plaster.

The crowns were fabricated from the type IV models with monolithic ceramic IPS e.max ${ }^{\circledR}$ Press LT (Ivoclar Vivadent, Schaan, Liechtenstein), shade A2, following the manufacturer's instructions.

After fitting adjustments, all crowns were luted with Variolink II cement (Figure 2), following the procedures described in Figure 3, and submitted to a static load of $5 \mathrm{~kg}$ during light-curing process. After removal of the excess of cement, light curing was performed on the buccal, lingual and occlusal surfaces, for $40 \mathrm{~s}$ on each surface (Figure 1c). The specimens were then stored in lightproof flasks, immersed in deionized water and kept at $37^{\circ} \mathrm{C}$. The specimens were randomly divided in subgroups of 5 for each substrate and sectioned either after 7 days or 3 months of water storage. The storage water was changed every 15 days during this period.

\section{Sectioning and Knoop hardness (KHN) measurements}

The teeth were removed from the embedding cups and transversely sectioned below the crown

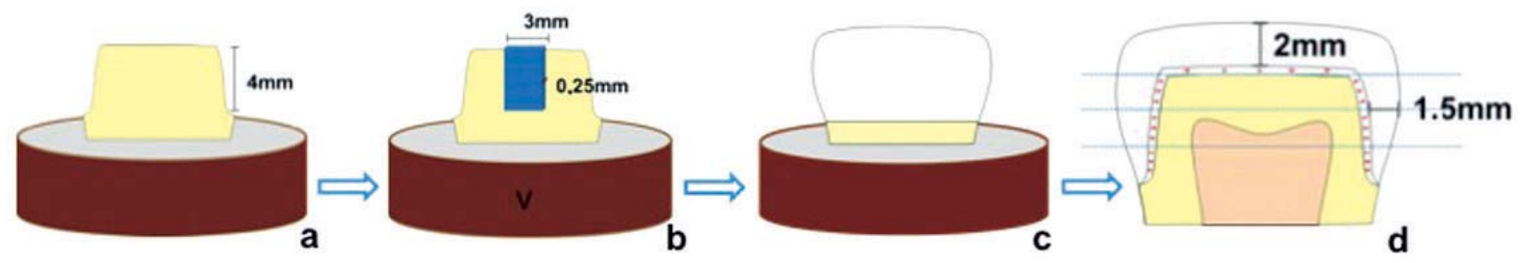

Figure 1- Scheme of experimental stages: a) prepared tooth; b) wax relief; c) cemented crown; d) sectioned crown exhibiting microhardness measurements along the cement line and ceramic thicknesses 
margins using a diamond disc (Buehler, Lake Bluff, IL, USA) under constant irrigation. The crowns were then sectioned in a buccolingual direction, at the center of the relief area, to expose the cement line. To facilitate positioning of the specimen in the microhardness tester, a second parallel section limited to ceramic was made to keep the surface to be analyzed perpendicular to the indenter.

The cut surface was sequentially polished with 600- and 1200-grit SiC paper, followed by $1-\mu \mathrm{m}$ diamond paste on a cloth, under constant irrigation. Between each polishing step, the specimens were rinsed with water for $30 \mathrm{~s}$ and ultrasonicated in deionized water for $2 \mathrm{~min}$. The polished crown sections were kept in moist gauze in lightproof flasks until tested.
Measurements were performed on a Shimadzu Microhardness Tester Hmv-2,000 (Shimadzu Corporation - Kyoto, Japan) with Knoop indenter under a static load of $50 \mathrm{~g}$ for $10 \mathrm{~s}$. Indentations were made from cervical to occlusal surface in 0.5 $\mathrm{mm}$ intervals along the cement line (Figure $1 \mathrm{~d}$ ). The hardness was expressed as a Knoop hardness number (KHN), and at the end of measurements the average microhardness values were obtained for the cervical, medium and occlusal thirds and occlusal surface.

\section{Data treatment}

Data were analyzed by three-way ANOVA (substrates, thirds/occlusal surface, and storage), and two-way ANOVA was applied (substrate/

\begin{tabular}{|c|c|c|c|}
\hline Cement & Adhesive System & Manufacturer & Lot \\
\hline VARIOLINK II: & EXCITE DSC: & \\
Monomer matrix (bis-GMA, urethane \\
$\begin{array}{c}\text { dimethacrylate and triethyleneglycol } \\
\text { dimethacrylate) and inorganic load (barium } \\
\text { glass, ytterbium trifluoride, barium fluorosilicate } \\
\text { glass and mixed aluminum and oxide spheres), } \\
\text { catalyzers, stabilizers and pigments. }\end{array}$ & $\begin{array}{c}\text { HEMA, dimethacrylate, phosphoric } \\
\text { acid acrylate, highly dispersed silicon } \\
\text { alcohol solution. Microbrush coated with }\end{array}$ & $\begin{array}{c}\text { Ivoclar } \\
\text { Vivadent, } \\
\text { initiators. }\end{array}$ & Liechtenstein \\
N42989 & \\
\end{tabular}

Figure 2- Chemical composition of the resin cement and adhesive system

\begin{tabular}{|l|l|}
\hline \multicolumn{1}{|c|}{ Surface } & \multicolumn{1}{c|}{ Procedures } \\
\hline Dentin & $\begin{array}{l}\text { Etching with } 37 \% \text { phosphoric acid for } 15 \mathrm{~s} \text {, rinsing for } 5 \mathrm{~s} \text {, and air-drying without dehydrating the } \\
\text { dentin surfaces. Application of DSC adhesive followed by light-curing for } 20 \mathrm{~s} .\end{array}$ \\
\hline Metal & Etching with $37 \%$ phosphoric acid for $15 \mathrm{~s}$, rinsing for $5 \mathrm{~s}$, and air-drying. \\
\hline Composite resin & $\begin{array}{l}\text { Etching with } 37 \% \text { phosphoric acid for } 15 \mathrm{~s}, \text { rinsing for } 5 \mathrm{~s} \text {, and air-drying. Application of adhesive } \\
\text { followed by light-curing for } 20 \mathrm{~s} .\end{array}$ \\
\hline Ceramic crown & $\begin{array}{l}\text { Etching with } 5 \% \text { hydrofluoric acid for } 20 \mathrm{~s}, \text { rinsing, and air-drying. Following, silane was applied for } 60 \\
\mathrm{~s}, \text { air-dried, and the adhesive Excite DSC was applied followed by light-curing for } 20 \mathrm{~s} .\end{array}$ \\
\hline
\end{tabular}

Figure 3- Technical procedures

Table 1- Knoop hardness number (Standard Deviation) at cervical, middle, occlusal thirds and occlusal surface according to the conditions substrate/time storage

\begin{tabular}{ccccccc}
\hline Group & DENTIN & & METAL & & RESIN \\
& $\mathbf{7}$ days & 3 months & 7 days & 3 months & 7 days & 3 months \\
\hline Cervical & $51.0(0.8)^{\mathrm{Aa}+}$ & $48.7(1.1)^{\mathrm{Aa}+}$ & $49.1(3.1)^{\mathrm{Aa}+}$ & $48.9(0.3)^{\mathrm{Aa}+}$ & $48.0(4.6)^{\mathrm{Ab}+}$ & $46.4(3.8)^{\mathrm{Ab+}}$ \\
Medium & $51.5(1.5)^{\mathrm{Aa}+}$ & $49.1(1.3)^{\mathrm{Aa}+}$ & $49.1(2.1)^{\mathrm{Aa}+}$ & $49.8(0.5)^{\mathrm{Aa}+}$ & $45.8(4.2)^{\mathrm{Ab+}}$ & $48.6(3.1)^{\mathrm{Ab}+}$ \\
Occlusal & $51.6(1.8)^{\mathrm{Aa}+}$ & $50.3(0.9)^{\mathrm{Aa}+}$ & $50.5(2.6)^{\mathrm{Aa}+}$ & $49.6(1.5)^{\mathrm{Aa}+}$ & $45.0(4.7)^{\mathrm{Ab}+}$ & $48.6(2.6)^{\mathrm{Ab+}}$ \\
$\begin{array}{c}\text { Occlusal } \\
\text { surface }\end{array}$ & $48.6(1.3)^{\mathrm{Aa}+}$ & $48.9(0.8)^{\mathrm{Aa}+}$ & $48.5(3.6)^{\mathrm{Aa}+}$ & $47.9(1.2)^{\mathrm{Aa}+}$ & $43.5(4.9)^{\mathrm{Ab}+}$ & $49.1(3.4)^{\mathrm{Ab+}}$ \\
Mean & 50.7 & 49.3 & 49.3 & 49.1 & 45.6 & 48.2 \\
\hline
\end{tabular}

$\mathrm{N}=5$ specimens in each group. Equal capital letters indicate lack of statistically significant difference (analysis of storage); equal lowercase letters indicate lack of statistically significant difference (analysis of substrate); equal symbols indicate lack of statistically significant difference (analysis of thirds). $p<0.05$ 
storage). Group differences were investigated by Tukey test $(\alpha=5 \%)$.

\section{RESULTS}

Data were analyzed by three-way ANOVA (substrates, thirds, and storage). Considering each factor independently, the substrates showed significant differences $(p=0.000)$, without differences for factors storage $(p=0.573)$ or thirds $(p=0.231)$ (Table 1$)$. There were interactions between substrates and storage time factors $(p=0.011)$. Since the analysis did not reveal significant differences between thirds, the values of substrate and storage were submitted to twoway ANOVA, which showed significant effects of core materials $(p<0.001)$. Hardness values were significantly lower when crowns were cemented on resin cores and measured after 7 days of storage $(p=0.007)$ (Table 2, Figure 4).

\section{DISCUSSION}

The fact that there were no differences among thirds and faces is probably due to the ceramic thickness employed ( $1.5 \mathrm{~mm}$ on axial walls and 2.0 $\mathrm{mm}$ on the occlusal aspect) and the composition of ceramic IPS e.max ${ }^{\circledR}$ Press, a vitreous ceramic

Table 2- Knoop hardness number (Standard Deviation) of samples according to the conditions substrate/time storage

\begin{tabular}{ccccc}
\hline & DENTIN & METAL & RESIN & Mean \\
\hline 7 days & $50.7(1.9)^{\mathrm{Aa}}$ & $49.3(3.0)^{\mathrm{Aa}}$ & $45.6(4.9)^{\mathrm{Bb}}$ & 48.5 \\
3 months & $49.3(1.2)^{\mathrm{Aa}}$ & $49.1(1.3)^{\mathrm{Aa}}$ & $48.2(3.4)^{\mathrm{Aa}}$ & 48.8 \\
Mean & 50 & 49.2 & 46.9 & - \\
\hline
\end{tabular}

$\mathrm{N}=5$ specimens in each group. Equal capital letters indicate lack of statistically significant difference (analysis by row); equal lowercase letters indicate lack of statistically significant difference (analysis by column). $p<0.05$
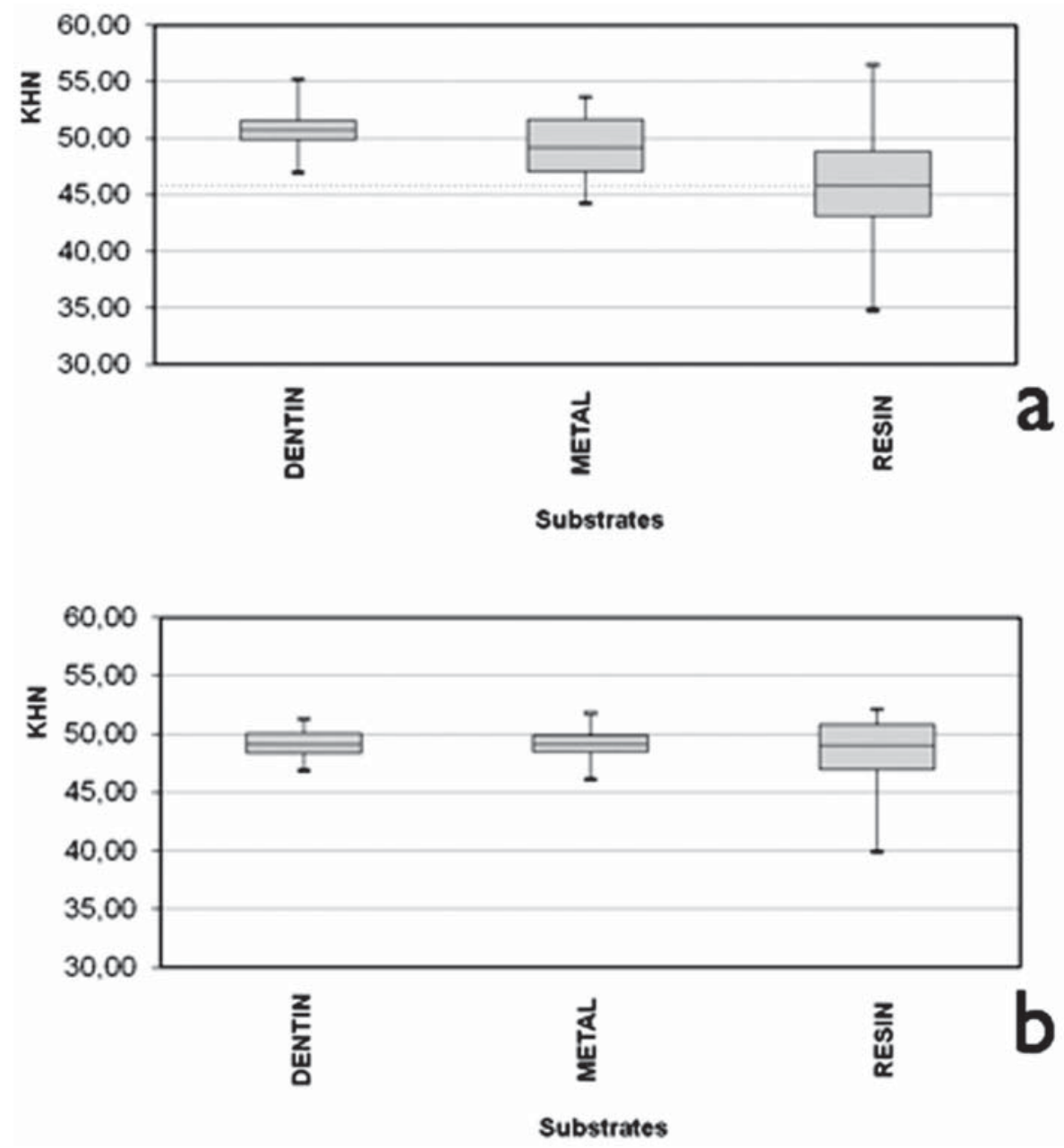

Figure 4- Box plots: a) results after 7 days in water storage; b) results after 3 months in water storage 
composed of lithium disilicate ${ }^{12}$, which may have allowed sufficient light transmission throughout the crown extent. Pazin, et al. ${ }^{21}$ (2008) also found uniform microhardness values along the cement layer for the cement Variolink II used to cement leucite-based ceramic crowns with $1.4 \mathrm{~mm}$ and 2.0 $\mathrm{mm}$ of thickness.

Concerning the type of substrate, only the composite resin core, after storage in water for 7 days, resulted in significantly lower hardness values when compared with the other groups and storage conditions. Therefore, the anticipated hypothesis must be partially rejected.

When full crowns are cemented on metal or fiber-reinforced resin posts or cores, the permeability of the simplified adhesive will not be in effect. But when the substrate is hydrated dentin, the permeability might be more relevant and harmful than the chemical incompatibility in relation to metal and composite resin substrates ${ }^{22}$. This occurs because the fluid transudation through the adhesive may result in water accumulation at the interface between adhesive and cement, causing significant reductions in bond strength. This water accumulation is originated from the hydrated dentin, and the negative effect of this permeability on the adhesive resistance of resin cements was confirmed by in vitro studies ${ }^{27}$. When crowns are cemented on core substrates other than dentin, the permeability is absent or reduced, but the chemical incompatibility persists between the acidity of simplified adhesives and the components of the chemical curing route of resins ${ }^{27}$. The reduction of mechanical properties of composites stored in water is predominantly related to water absorption by the polymer, which is softened by the tumescence of polymeric chains and reduction of frictional strength of these chains ${ }^{8,33}$. Once saturated in water, the polymeric chains are stabilized and there is no further reduction of material properties ${ }^{8,20,33}$. The effects of humidity on the mechanical properties of resin cements have been extensively investigated, and there is consensus that the action of solvents on the polymeric chain is deleterious to the mechanical properties of the cement $3,8,18,19,32,33$.

As previously mentioned, it has been reported that resin monomers originated from two-step conventional and one-step self-etching adhesives may impair the co-curing and consequent bond between these types of adhesives and composites, whose curing reaction is initiated by a redox reaction between the tertiary amine and benzoyl peroxide. As a consequence, low adhesive strength values are reported when these materials are combined ${ }^{4,23}$. In an attempt to avoid this chemical incompatibility and enhance the adhesive strength, manufacturers have been adding co-initiators in adhesive systems that react with acidic resin monomers and produce phenyl or benzenesulphonic radicals that initiate the curing reaction in dual resin cements or when there is no adequate light exposure ${ }^{10}$.

The microbrush of the adhesive system used in this study contains initiators that are fundamental for the self-cure mechanism. Additionally, this mechanism requires other initiators that are originated from a composite that also presents a self-cure mechanism ${ }^{13,14}$ and may come from a dual or chemically cured reconstruction composite (when the adhesive is used for reconstruction) or dual or chemically cured cement (in cases of luting). That is to say, the self-cure mechanism of DSC ${ }^{\circledR}$ adhesive may not occur if it does not get in contact with dual or self-cured resin ${ }^{13,14}$. For this reason, if the DSC adhesive is exclusively used with a light-cured resin, it should necessarily be light-cured before placement of composite resin ${ }^{13,14}$.

Based on this assumption, it is understood that there clearly is a chemical reaction between the DSC adhesive and self-cured or dual-cured resins. This reaction should favor both the adhesive and cement curing. In this context, the DSC adhesive layer applied on the substrates, though light-cured, contained initiators of chemical reaction ready to react with initiators present in the cement Variolink ${ }^{\circledR}$ II and provide fast consolidation of curing of the DSC adhesive, also favoring the cement curing, especially in areas less accessible to light, thus characterizing a "collaboration" reaction of initiators of the adhesive and cement to enhance the curing of both. Considering that the quantity of such initiators in the adhesive is limited to the applied layer, when the adhesive was applied on dentin, all radicals were free to react with the cement. However, when the adhesive was applied on the core resin, it is speculated that some initiators of the adhesive reacted with uncured free radicals of the core resin and consequently reduced the availability of initiators to react with the cement. The consequence was that the cement cure and certainly also the adhesive cure were delayed, resulting in lower microhardness values in the initial storage period (7 days). Analysis of Table 1 reveals that, although not statistically significant, the microhardness of group $\mathrm{R}$ after 7 days of storage decreased from the cervical margin to the occlusal aspect, suggesting that in areas close to margins, in which the light acts on the cement curing with greater intensity, the conflict of utilization of initiators between core resin and cement is surpassed by the curing achieved by light-curing. Since the effects of this conflict are temporary, causing only a delay in the curing process, the same phenomenon is not observed after 3 months of storage.

The composite resin, when used as filling material for cores, provides advantages as easy handling, fast curing, good translucency shade, 
which does not interfere with the ceramic shade. However, in the routine clinical practice, the resin is often in contact with saliva for a considerable time. It is not known to which extent the lower hardness outcomes observed when cementing over the composite resin core may cause any relevant clinical problem. Further studies should be conducted to enhance the understanding on the reactions occurring between this substrate and the resin cement.

\section{CONCLUSIONS}

Based on the results, the following could be concluded:

There was no significant difference in the microhardness results between the cervical, medium, and occlusal thirds and occlusal surface;

There was significant difference in the microhardness results between substrates. For the 7-day storage period, the results of the composite resin substrate were lower than dentin and metal. After 3 months of storage, the results were similar for the 3 substrates;

The type of material employed for coronal reconstruction of preparations for prosthetic purposes may influence the cement properties.

\section{ACKNOWLEDGMENTS}

This study was financially supported by FAPESP - São Paulo Research Foundation (2010/060926 ) and was approved by the Institutional Review Board of Bauru School of Dentistry-USP (process no. $165 / 2009$ ).

\section{REFERENCES}

1- Blackman R, Barghi N, Duke E. Influence of ceramic thickness on the polymerization of light-cured resin cement. J Prosthet Dent. 1990;63(3):295-300.

2- Borges GA, Agarwal P, Miranzi BA, Platt JA, Valentino TA, Santos $\mathrm{PH}$. Influence of different ceramics on resin cement Knoop hardness number. Oper Dent. 2008;33(6):622-8.

3- Bortolotto T, Guillarme D, Gutemberg D, Veuthey JL, Krejci I. Composite resin vs resin cement for luting of indirect restorations: comparison of solubility and shrinkage behavior. Dent Mater J. 2013;32(5):834-8.

4- Cavalcanti SC, Oliveira MT, Arais CA, Giannini M. The effect of the presence and presentation mode of co-initiators on the microtensile bond strength of dual-cured adhesive systems used in indirect restorations. Oper Dent. 2008;33(6):682-9.

5- Ceballos L, Garrido MA, Fuentes V, Rodríguez J. Mechanical characterization of resin cements used for luting fiber posts by nanoindentation. Dent Mater. 2007;23(1):100-5.

6- El-Mowafy OM, Rubo MH. Influence of composite inlay/onlay thickness on hardening of dual-cured resin cements. J Can Dent Assoc. 2000;66(3):147.

7- El-Mowafy OM, Rubo MH, el-Badrawy WA. Hardening of new resin cements cured through a ceramic inlay. Oper Dent. $1999 ; 24(1): 38-44$.
8- Ferracane JL, Berge HX, Condon JR. In vitro aging of dental composites in water-effect of degree of conversion, filler volume, and filler/matrix coupling. J Biomed Mater Res. 1998;42(3):46572.

9- Hooshmand T, Mahmoodi N, Keshvad A. Microhardness of a resin cement polymerized by light-emitting diode and halogen lights through ceramic. J Prosthodont. 2009;18(5):411-6.

10- Ikemura K, Endo T. Effect on adhesion of new polymerization initiator systems comprising 5-monosubstituted barbituric acids, aromatic sulfinate amides, and tert-butyl peroxymaleic acid in dental adhesive resin. J Appl Polym Sci. 1999;72(13):1655-68. 11- Ilie N, Hickel R. Correlation between ceramics translucency and polymerization efficiency through ceramics. Dent Mater. 2008;24(7):908-14.

12- Ivoclar Vivadent AG. Scientific documentation IPS e.max ${ }^{\circledR}$ Press. Liechtenstein: Ivoclar Vivadent; 2005.

13- Ivoclar Vivadent AG. Scientific documentation Excite $₫$ DSC. Liechtenstein: Ivoclar Vivadent; 2008.

14- Ivoclar Vivadent AG. Scientific documentation Excite ${ }^{\circ}$ F DSC. Liechtenstein: Ivoclar Vivadent; 2010.

15- Manso AP, Silva NR, Bonfante EA, Pegoraro TA, Dias RA, Carvalho RM. Cements and adhesives for all-ceramic restorations. Dent Clin North Am. 2011;55(2):311-32.

16- Meng X, Yoshida K, Atsuta M. Influence of ceramic thickness on mechanical properties and polymer structure of dual-cured resin luting agents. Dent Mater. 2008;24(5):594-9.

17- Noronha Filho JD, Brandão NL, Poskus LT, Guimarães JGA, Silva EM. A critical analysis of the degree of conversion of resin-based luting cements. J Appl Oral Sci. 2010;18(5):442-6.

18- Ortengren U, Elgh U, Spasenoska V, Milleding P, Haasim J, Karlsson S. Water sorption and flexural properties of a composite resin cement. Int J Prosthodont. 2000;13(2):141-7.

19- Oysaed H, Ruyter IE. Composites for use in posterior teeth: mechanical properties tested under dry and wet conditions. J Biomed Mater Res. 1986;20(2):261-71.

20- Park JW, Ferracane JL. Water aging reverses residual stresses in hydrophilic dental composites. J Dent Res. 2014;93(2):195-200. 21- Pazin MC, Moraes RR, Gonçalves LS, Borges GA, Sinhoreti MA, Correr-Sobrinho L. Effects of ceramic thickness and curing unit on light transmission through leucite-reinforced material and polymerization of dual-cure luting agent. J Oral Sci. 2008;50(2):131-6.

22- Pegoraro TA, Silva NR, Carvalho RM. Cements for use in Esthetic Dentistry. Dent Clin North Am. 2007;51(2):453-71.

23- Sanares AM, Itthagarun A, King NM, Tay FR, Pashley $\mathrm{DH}$. Adverse surface interactions between one-bottle lightcured adhesives and chemical-cured composites. Dent Mater. $2001 ; 17(6): 542-56$.

24- Soares CJ, Silva NR, Fonseca, RB. Influence of the feldspatic ceramic thickness and shade on the microhardness of dual resin cement. Oper Dent. 2006;31(3):384-9.

25- Stamatacos C, Simon JF. Cementation of indirect restorations: an overview of resin cements. Compend Contin Educ Dent. $2013 ; 34(1): 42-4,46$.

26- Tay FR, Frankeberg R, Krejci I, Bouillaguet S, Pashley DH, Carvalho RM. Single-bottle adhesives behave as permeable membranes after polymerization. I. In vivo evidence. J Dent. 2004;32(8):611-21.

27- Tay FR, Pashley DH, Suh BI, Carvalho RM, Itthagarun A. Single-step adhesives are permeable membranes. J Dent. 2002;30(7-8):371-82.

28- Tay FR, Pashley DH, Yiu CK, Sanares AM. Wei SH. Factors contributing to the incompatibility between simplified-step adhesives and chemically-cured or dual-cured composites. Part I. Single-step self-etching adhesive. J Adhes Dent. 2003;5(1):27-40. 29- Tay FR, Suh BI, Pashley DH, Prati C, Chuang SF, Li F. Factors contributing to the incompatibility between simplified-step adhesives and self-cured or dual-cured composites. Part II. Singlebottle total-etch adhesive. J Adhes Dent. 2003;5(2):91-105. 
30- Uctasli S, Hasanreisoglu U, Wilson $\mathrm{HJ}$. The attenuation of radiation by porcelain and its effect on polymerization of resin cements. J Oral Rehabil. 1994;21(5):565-75.

31- Valentino TA, Borges GA, Borges LH, Vishal J, Martins LR, Correr-Sobrinho L. Dual resin cement Knoop hardness after different activation modes through dental ceramics. Braz Dent. 2010;21(2):104-10.

32- Vrochari AD, Eliades G, Hellwig E, et al. Water sorption and solubility of four self-etching, self-adhesive resin luting agents. J Adhes Dent. 2010;12(1):39-43.
33- Walker MP, Spencer P, David Eick J. Mechanical property characterization of resin cement after aqueous aging with and without cyclic loading. Dent Mater. 2003;19(7):645-52.

34- Zhang $X$, Wang F. Hardness of resin cement cured under different thickness of lithium disilicate-based ceramic. Chin Med J. $2011 ; 124(22): 3762-7$. 